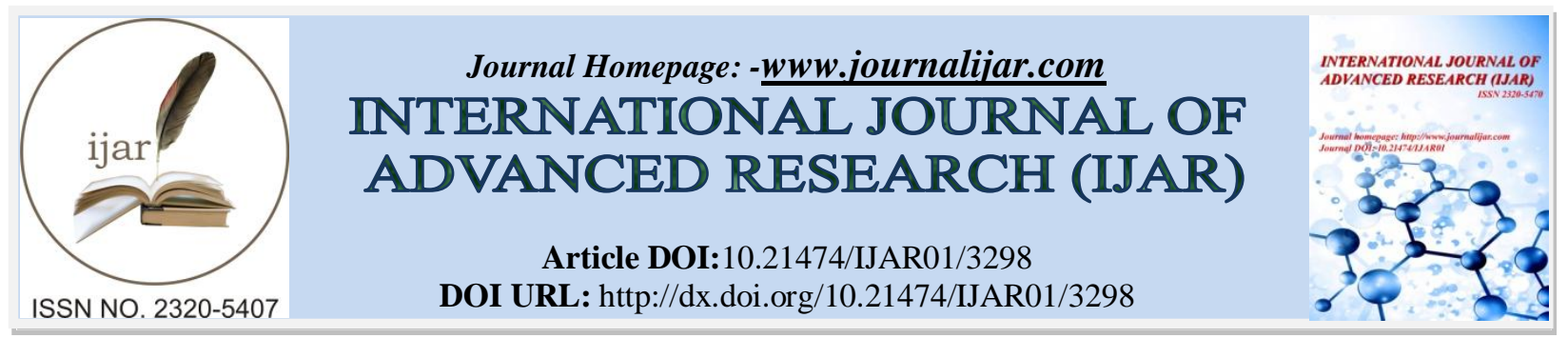

RESEARCH ARTICLE

\title{
STRATEGIES FOR MEDICAL CARE OF DIABETIC PATIENTS DURING RAMADAN
}

\author{
Sayed Ibrahim Ali ${ }^{1}$, Latifah khalid Al Jouf ${ }^{2}$, Amnah Ahmed Al-Huwayji ${ }^{2}$, Norah Khalid Al-Jouf ${ }^{2}$, Amal \\ Almass Al-Blushi ${ }^{2}$ and Seba Mohammad Ghreiz ${ }^{3}$. \\ 1. Assistant Professor of Biostatistics, College of Medicine, King Faisal University, Saudi Arabia. \\ 2. Medical Students,College of Medicine, King Faisal University, Saudi Arabia \\ 3. Assistant Professor of Family Medicine, College of Medicine, King Faisal University, Saudi Arabia.
}

\section{Manuscript Info}

Manuscript History

Received: 26 December 2016

Final Accepted: 30 January 2017

Published: February 2017

Key words:-

Medical Care,Diabetic Patients,

Ramadan, Saudi Arabia.

\section{Abstract}

Introduction: Ramadan is the ninth month of the Muslim calendar and the daylight fasting that accompanies it is one of the five pillars of Islam. Fasting during Ramadan is obligatory for all healthy adult Muslims, although exemptions exist for people with serious medical conditions, elderly, and children.

Method: This cross-sectional survey study was done during a period from 10 June to 1 December 2016, A questionnaire design in Arabic language (national language of KSA) was distributed among eastern regions Saudi population through social media (as Facebook, twitter and what's up). A total of 110 participants (known case of DM $=39$, healthy $=71)$, aged from 15-60 years.

Result: One hundred ten (110) participants shared in our study. Their mean age was $30 \mathrm{SD}$ that ranges from 20-60 years. They were classified according to age into 3 age group. Group 1 (younger than 20 years) group 2 (20-40yrs) group 3 (older than 40yrs). Most of them was healthy, only 39 participants was affected by DM. They were subdivided according to their level of Education and knowledge about DM into have enough information and don't have enough information.

Discussion: In this study, we are interested to evaluate the role of health-care educator during Ramadan, include Campaigns, social media, medical staff in the Saudi population specifically the population of eastern region.. In 2015, the number of people living with diabetes globally was estimated to be 415 million, with a $55 \%$ rise expected by 2040 [2]. The number of patients with diabetes in the Middle East and Africa - a region where a high proportion of inhabitants are Muslim is predicted to more than double by 2040. A similar increase is expected in South East Asia, another area where Islam predominates (2). 


\section{Introduction:-}

Ramadan is the ninth month of the Muslim calendar and the daylight fasting that accompanies it is one of the five pillars of Islam. Fasting during Ramadan is obligatory for all healthy adult Muslims, although exemptions exist for people with serious medical conditions, elderly, and children.

Pre-Ramadan education provides a base to diabetic patients about the importance of diet and exercise, and that regular glucose monitoring is essential to avoid complications..

Education of medical staff, including physicians, nurses and pharmacist, is also needed..

However, Ramadan can result in an extra burden of calories. After, the meal taken when the fast is broken at sunset often turns into a celebration, with huge volumes of food laden with sugar and carbohydrates. Regional variations exist in the timings of meals during Ramadan and physicians need to understand regional and cultural differences to advise the patient accordingly (1).

Because of the metabolic nature of the disease, patients with diabetes are at particular risk of complications from marked changes in food and fluid intake (1). Potential health hazards include hypoglycemia, hyperglycemia, dehydration and acute metabolic complications such as diabetic ketoacidosis DKA (11).

Fasting during Ramadan may provide enduring benefits. Indeed, Ramadan can provide an opportunity for a better lifestyle, facilitating weight loss and smoking cessation (12).

Most diabetic patients prefer fasting during Ramadan to earn the reward of Allah..It's also a good time to control blood sugar and loss weight.

The month of Ramadan can precipitate dramatic changes in meal schedule, sleep patterns and circadian rhythms (1).even though that fasting Muslims tend to avoid consulting their doctors (13)

Therefore, patients with diabetes, and in particular those with T1DM, should seek medical advice before deciding to proceed with Ramadan fasting (1).

\section{Objective:-}

in this study Our aim here is to the assessment the role of education programme including Campaigns, social media, text messages and medical staff for diabetic patients during Ramadan about physical activity, meal planning, glucose monitoring, hypoglycemia, dosage and timing of medications.. Education, communication and accessibility are all critical to the success in reduce complication of diabetic patients during Ramadan. With the correct guidance, many people with diabetes can fast safely.

\section{Method:-}

This cross-sectional survey study was done during a period from 10 June to 1 December 2016, A questionnaire design in Arabic language (national language of KSA) was distributed among eastern regions Saudi population through social media (as Facebook, twitter and what's up). A total of 110 participants (known case of DM $=39$, healthy = 71), aged from 15-60 years. Some of the participant were interviewed randomly..The questionnaire included the role of education programme, Campaigns, social media and medical staff for diabetic patients during Ramadan about physical activity, meal planning, glucose monitoring, hypoglycemia, dosage and timing of medications, The questionnaire answered anonymously and in private..

\section{Result:-}

One hundred ten (110) participants shared in our study. Their mean age was 30 SD that ranges from 20-60 years. They were classified according to age into 3 age group. Group 1 (younger than 20 years) group 2 (20-40years) group 3 (older than 40years)

Most of them was healthy, only 39 participants was affected by DM. They were subdivided according to their level of Education and knowledge about DM into have enough information and don't have enough information. 
Table 1:- Awareness of the study population about the healthy life style of DM patients during Ramadan andthe role of publicize educationprogramme

\begin{tabular}{|c|c|c|c|}
\hline & & $\mathrm{N}$ & $\%$ \\
\hline \multirow{3}{*}{ Age group } & Under 20 & 4 & 3.6 \\
\hline & From $20-40$ years & 75 & 68.2 \\
\hline & Above 40 years & 28 & 25.5 \\
\hline \multirow[t]{2}{*}{ 1) Are you diabetic? } & Yes & 39 & 35.5 \\
\hline & No & 71 & 64.5 \\
\hline \multirow[t]{2}{*}{ 2) Do you have enough information about diabetes? } & No & 39 & 35.5 \\
\hline & Yes & 71 & 64.5 \\
\hline \multirow{3}{*}{$\begin{array}{l}\text { 3) Have you Attended events to raise awareness about diabetes for the } \\
\text { month of Ramadan and benefited from their publications? }\end{array}$} & No & 74 & 67.3 \\
\hline & Idon't care & 11 & 10.0 \\
\hline & Yes & 25 & 22.7 \\
\hline \multirow{2}{*}{$\begin{array}{l}\text { 4) Have you benefited from social media in dealing with diabetes in } \\
\text { Ramadan? }\end{array}$} & No & 50 & 45.5 \\
\hline & Yes & 60 & 54.5 \\
\hline \multirow{2}{*}{$\begin{array}{l}\text { 5) Have you consulted your physician before Ramadan to take advices } \\
\text { and instructions and make the required check-ups, if necessary? }\end{array}$} & No & 74 & 67.3 \\
\hline & Yes & 32 & 29.1 \\
\hline \multirow{2}{*}{$\begin{array}{l}\text { 6) Have you prepared a food plan in preparation for the month of } \\
\text { Ramadan with your doctor? }\end{array}$} & No & 74 & 67.3 \\
\hline & Yes & 32 & 29.1 \\
\hline \multirow{2}{*}{$\begin{array}{l}\text { 7) Does your family members take into account that you are diabetic } \\
\text { when preparing breakfast and Suhoor? }\end{array}$} & No & 56 & 50.9 \\
\hline & Yes & 46 & 41.8 \\
\hline \multirow{3}{*}{$\begin{array}{l}\text { 8) Do you examine diabetic levels several times a day in the month of } \\
\text { Ramadan? }\end{array}$} & Sometimes & 29 & 26.4 \\
\hline & I do not & 46 & 41.8 \\
\hline & I do it & 29 & 26.4 \\
\hline
\end{tabular}

Table 1 demonstrates the sociodemographic distribution of the studied population according to their age .There's a significant difference in the level of education between difference between age group, (20-40) group much more educated than other age groups..

Table 2:-shows Chi-Square test of the studied groups age, affection and level of education and awareness about DM

\begin{tabular}{|c|c|c|c|}
\hline & Df & chi square value & p-value \\
\hline 1.age * Are you diabetic? & 3 & 9.186 & 0.027 \\
\hline $\begin{array}{l}\text { 5. age*Have you consulted your physician before Ramadan to take advices } \\
\text { and instructions and make the required check-ups, if necessary? }\end{array}$ & 6 & 12.892 & 0.045 \\
\hline $\begin{array}{l}\text { 2. Are you diabetic?*Have you Attended events to raise awareness about } \\
\text { diabetes for the month of Ramadan and benefited from their publications? }\end{array}$ & 2 & 24.151 & 0.000 \\
\hline $\begin{array}{l}\text { 4. Are you diabetic?*Have you consulted your physician before Ramadan } \\
\text { to take advices and instructions and make the required check-ups, if } \\
\text { necessary? }\end{array}$ & 2 & 26.933 & 0.000 \\
\hline $\begin{array}{l}\text { 5. Are you diabetic?*Have you prepared a food plan in preparation for the } \\
\text { month of Ramadan with your doctor? }\end{array}$ & 2 & 9.863 & 0.007 \\
\hline $\begin{array}{l}\text { 6.Are you diabetic? }{ }^{*} \text { Does your family members take into account that you } \\
\text { are diabetic when preparing breakfast and Suhoor? }\end{array}$ & 2 & 5.745 & 0.057 \\
\hline $\begin{array}{l}\text { 7.Are you diabetic? } * \text { Do you examine diabetic levels several times a day in } \\
\text { the month of Ramadan? }\end{array}$ & 3 & 44.984 & 0.000 \\
\hline $\begin{array}{l}\text { 9. Are you diabetic?*Do you know what the best time for exercises in } \\
\text { Ramadan is? }\end{array}$ & 3 & 11.945 & 0.008 \\
\hline $\begin{array}{l}\text { 10. Are you diabetic?*Do you think that the Tarawih prayers are useful for } \\
\text { diabetics? }\end{array}$ & 3 & 22.815 & 0.000 \\
\hline $\begin{array}{l}\text { 14. Are you diabetic?*In your opinion, what is the best way to increase the } \\
\text { awareness of the community about diabetes? }\end{array}$ & 6 & 17.159 & 0.009 \\
\hline
\end{tabular}

Age is the only parameters that shows significant correlation $\mathrm{P}$ value. 
Table 2 shows the role of publicize education programme that increase awareness Including campaigns, posters in public places such as local libraries, supermarkets, mosques and community centers, social media and medical staff to decrease complication of fasting in DM patients. An evaluation of result revealed poor levels of knowledge as the majority of respondent provided the wrong answers. Only one-fourth of study respondents were able to give correct answer about healthy life style of DM patients during Ramadan.. The information and advice that the patients received in that programmes provided additional knowledge for the patients to continue their diabetes selfmanagement and to take responsibility for their care beyond the month of the Ramadan fast.

Regarding the role of education programme, $22 \%$ of the patients had attended structured education previously. $67 \%$ didn't attend..

$54 \%$ use social media and have benefit from programme about DM , 45\%don't use it . Regarding the medical staff ,29\% manage their healthy lifestyle during Ramadan with their doctor ,67\% don’t do it ..

Table 2 shows the awareness level of the studied population to risk factors, recommendation and management of complication during fasting.

Structured diabetes counseling before Ramadan includes educating patients, health care providers, and patient's families.. provide education for the patients and families to get ready for change lifestyle pattern during Ramadan, $41 \%$ of family take care to prepare of healthy diet for their DM patients during Ramadan ,while 50\% ignore that issue..

Counseling has to be provided by the health care provider to the patient to prevent complication, So that patients welcome to fast Ramadan in stable and healthy regimen..29\% of patient's take advise from their doctor before Ramadan, while $67 \%$ ignore that issue..

The misconceptions were in relation to physical activity during fasting $(27 \%)$.

Blood glucose monitoring was done by $26 \%$ of participants, were they regularly monitoring their blood glucose at home by Self-Monitoring of Blood Glucose..

Symptoms of feeling of hypoglycemia was correctly answered by $83 \%$ of subjects..

\section{Discussion:-}

In this study, we are interested to evaluate the role of health-care educator during Ramadan, include Campaigns, social media , medical staff in the Saudi population specifically the population of eastern region.. In 2015, the number of people living with diabetes globally was estimated to be 415 million, with a $55 \%$ rise expected by 2040 [2]. The number of patients with diabetes in the Middle East and Africa - a region where a high proportion of inhabitants are Muslim - is predicted to more than double by 2040. A similar increase is expected in South East Asia, another area where Islam predominates (2). Most Muslim majority countries are in less-developed regions of the world, and developing countries are disproportionately affected by diabetes $[2,3,4]$. Therefore, Ramadan has a major impact on the management of diabetes in the Muslim population..

Fasting during Ramadan has a number of physiological effects on both homeostatic and endocrine processes. In patients with diabetes, these changes and the type of medication being taken to treat the condition can be associated with the development of complications such as hypoglycemia and hyperglycemia (4).

Fasting with diabetes poses significant risks. Most of the research on fasting and diabetes surrounds Ramadan, the annual Islamic observance that requires fasting from sunrise to sundown for 29 or 30 days. A commentary published in 2010 in Diabetes Care developed in collaboration with the American Diabetes Association (ADA) focused on fasting during Ramadan, though many of the issues it raises are relevant to other types of fasting as well. It says that "most often, the medical recommendation will be not to undertake fasting" if you have diabetes..

A study that include 110 participants, found that 71 percent of people with have enough information about diabetes mellitus and 39 percent of people don't have enough information. 
"Anybody with diabetes needs to first talk to their doctor about going on a fast," says Early, and some experts recommend a pre-fasting medical assessment to help ensure safety include medication, nutrition, and hydration into account 32 percent of people Carried it, while 74 percent So neglected.. Educational campaigns that target the general public should aim to raise awareness of the issues and misconceptions that surround diabetes and Ramadan fasting and emphasize the importance of maintaining good diabetes management during fasting. In addition to medical advice, religious regulations should be included (1)

Between 61.4 and $92.9 \%$ of healthcare professionals felt that people with diabetes needed to improve various selfmanagement activities; glucose monitoring (range, 29.3-92.1\%) had the biggest country difference, with a betweencountry variance of $20 \%(10)$.. It is also of educational value as it provides patients with feedback on the effect of lifestyle changes such as food and exercise on glucose control (3). Regularly monitoring blood glucose during fasting is key to avoiding health emergencies, $29 \%$ of people did it regularly, while $46 \%$ of people didn't do it at all, $29 \%$ of people did it at sometimes.

It is worth reemphasizing that fasting for patients with diabetes represents an important personal decision that should be made in light of guidelines for religious exemptions and after careful consideration of the associated risks following sample discussion with the treating physician. Most often, the recommendation will be to not undertake fasting. However, patients who insist on fasting need to be aware of the associated risks and be ready to adhere to the recommendations of their health care providers to achieve a safer fasting experience. Patients may be at higher or lower risk for fasting-related complications depending on the number and extent of their risk factors .

During Ramadan, there is a dramatic change in dietary patterns for fasting Muslims compared with other months of the year. Health issues may arise due to improper eating habits and reduced physical activity (5)

The diet during Ramadan should not differ significantly from a healthy and balanced diet. It should aim at maintaining a constant body mass. In that study, $46 \%$ of individuals who fast maintain their healthy diet during the month, while $56 \%$ of individuals didn't maintain their healthy diet..

Ingesting of large amounts of foods rich in carbohydrate and fat, especially at the sunset meal, should be avoided .

Diabetic patients with regular exercise habits showed a 2.8 -fold increased chance of outcome improvement compared with those who did not exercise regularly(6)..Normal levels of physical activity may be maintained 74\% of individuals did their exercise after breakfast by one or two hour. However, excessive physical activity may lead to higher risk of hypoglycemia and should be avoided, particularly during the few hours before the sunset meal. If Tarawaih prayer (multiple prayers after the sunset meal) is performed, then it should be Correspond to amount of diet which was consumed . In some patients with poorly controlled type 1 diabetes, exercise may lead to extreme hyperglycemia

\section{Strengths \& Weakness:-}

KSA is a large country previous studies was concentrated on the capital population. Our study strength points is that this study was carried out in a new region in KSA. And it investigated people awareness about this disease and the role of health care to management of diabetes during Ramadan..

Our weak relative point small sample size, and the way of collecting data by social media can be less accurate. But some of the questionnaire was filled by direct contact with participant..

\section{Conclusions:-}

We face an enormous burden of diabetes in the Saudi country, but our understanding of managing diabetes during the month of Ramadan/fasting is still far from perfect

Lifestyle and religious activities can have implications when managing patients with diabetes. During Ramadan, it can be very Difficult for the health professional and the individual to control patient's blood sugar level within accept level and avoid hypoglycemia. 
Diabetes education helps to overcome certain barriers to diabetes care. Making easy and low cost access to the recommendation in management of diabetic patients during Ramadan is necessary to avoid it's complication and to support people with diabetes to fast during Ramadan

With the Diabetes education, including the use of point-of-care (POC) glucose testing, take healthy diet and do regular exercise, readiness to break the fast in case of hypoglycemia resulted in fewer episodes of complications.

Although few recent large scale studies, including randomized trials, have been conducted with diabetes patient , there is need for more well-designed research with appropriate controls

\section{Reference:-}

1. Mohamed H, Monira Al-Arouj, Abdullah B , Wasim H, Abdulrazzaq Al-Madani, Adel A El-Sayed, et.al; Diabetes and Ramadan Practical Guidelines nternational Diabetes Federation (IDF), in collaboration with the Diabetes and Ramadan (DAR) International Alliance, April 2016, Available at: http://www.diabetesatlas.org/resources/2015

2. American Diabetes Association. Standards of medical care in diabetes. Diabetes Care 2015;38:S1-93.

3. Al-Faris EA. Guidelines for the management of diabetic patients in the health centers of Saudi Arabia J Family Community Med 1997;4:12-23.

4. Al-Arouj M, Bouguerra R, Buse J, et al. Recommendations for management of diabetes during Ramadan. Diabetes Care 2005;28:2305-11

5. Bravis V, Hui E, Salih S, et al. Ramadan Education and Awareness in Diabetes (READ) programme for Muslims with Type 2 diabetes who fast during Ramadan. Diabet Med 2010;27:327-31

6. Tang PL, Yuan WL, and Tseng HF. Clinical follow-up study on diabetes patients participating in a health management plan. J Nurs Res 2005;13:253-62

7. Hunt CW. Technology and diabetes self-management: An integrative review. World J Diabetes 33-6:225:2015

8. Niazi AK and Kalra S. Patient centred care in diabetology: an Islamic perspective from South Asia. J Diabetes MetabDisord 2012;11:30

9. Peeters B, Mehuys E, Van Tongelen I, et al. Ramadan fasting and diabetes: an observational study among Turkish migrants in Belgium. Prim Care Diabetes 2012;6:293-6

10. Holt RI, Nicolucci A, Kovacs Burns K, et al. Diabetes Attitudes, Wishes and Needs second study (DAWN2) cross-national comparisons on barriers and resources for optimal care - healthcare professional perspective. Diabet Med 2013;30:789-98

11. Pinelli NR and Jaber LA. Practices of Arab American patients with Type 2 diabetes mellitus during Ramadan. J Pharm Pract 2011;24:211-5

12. Evert AB, Boucher JL, Cypress M, et al. Nutrition therapy recommendations for the management of adults with diabetes. Diabetes Care 2014;37Suppl 1:S120-43

13. International Diabetes Federation. IDF Diabetes Atlas (Seventh Edition). 2015 Available at: http://www.diabetesatlas.org/resources/2015-atlas.html. Accessed 17 February 2016 